\title{
Crítica cultural y sociedad mexicana (notas para una discusión en marcha)
}

\author{
Sigifredo Esquivel* \\ Claudia Campos**
}

El presente artículo explora algunos de los temas y problemas más acuciantes de la crítica cultural en el contexto de la sociedad mexicana contemporánea. Se elabora un análisis interpretativo y un diagnóstico crítico sobre la cultura, la sociedad y los actores en México en la perspectiva del sistema-mundo capitalista y bajo las premisas del pensamiento complejo crítico.

\section{La Crítica CUltural (MODElos, teorías Y CONTRAMODELOS EMERGENTES)}

Diagnóstico. El hecho de que con el tiempo el mundo se ha convertido en el sistema que los nacionalsocialistas injustificadamente vituperaban en la laxa república de Weimar, se pone de manifiesto en la armonía preestablecida entre las instituciones y los que las sirven. Silenciosamente ha ido madurando una humanidad que apetece la coacción y la limitación que la absurda

* Docente-investigador de la Unidad Académica de Docencia Superior de la Universidad Autónoma de Zacatecas, México.

** Maestría en Docencia y Procesos Institucionales de la Universidad Autónoma de Zacatecas, México. persistencia del dominio le impone. Mas estos hombres, favorecidos por la organización objetiva, poco a poco han ido usurpando aquellas funciones que propiamente son las que debían introducir la disonancia en el seno de la armonía preestablecida. Entre todos los dichos registrados se encuentra también el de que "toda presión produce una contrapresión”: si aquélla es lo suficientemente grande, ésta desaparece, y la sociedad da la impresión de querer prevenir la entropía de forma masiva mediante un mortal equilibrio de las tensiones. La actividad científica tiene su exacta correspondencia en el tipo de espíritu que pone en tensión: los científicos ya no necesitan ejercer violencia alguna sobre sí para acreditarse como voluntarios y celosos controladores de sí mismos. Hasta cuando se encuentran fuera 


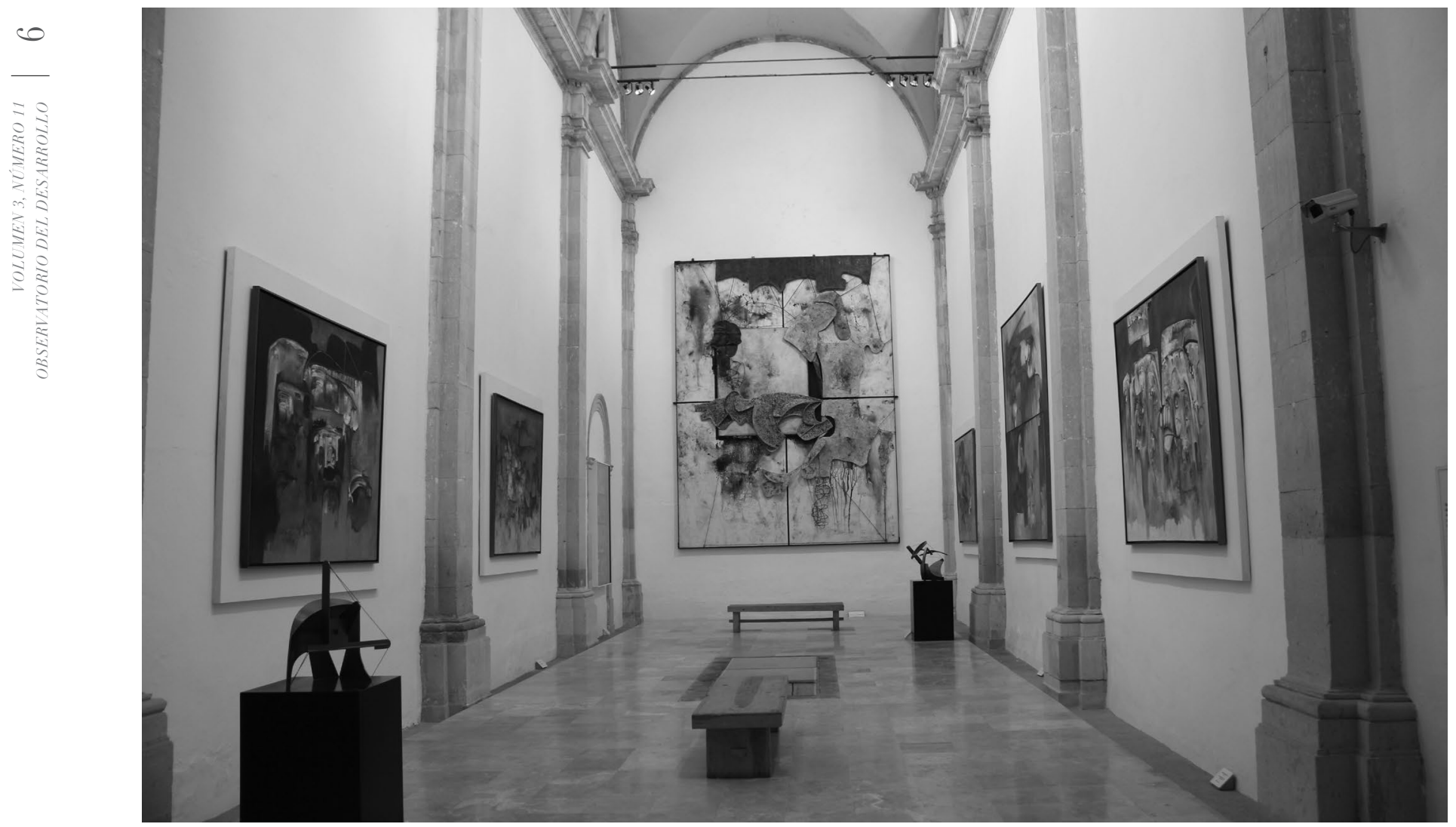

El Museo de Arte Abstracto Manuel Felguérez alberga un importante acervo del artista oriundo de Valparaíso, Zac.., $y$ de otros integrantes de la "generación de la ruptura". No obstante, este y los demás museos zacatecanos registran una baja afluencia de público local.

de su actividad como seres totalmente humanos y racionales, en el momento en que piensan por obligación profesional se anquilosan en una pática estupidez. ${ }^{\prime}$

La cita del pensador alemán Theodor Adorno intenta hacer un diagnóstico sobre la crisis de las ciencias y las humanidades como crisis del pensamiento crítico y abdicación de la responsabilidad de la teoría ante la realidad social y política. Nos muestra cómo es que ahora se privilegia el hecho de investigar más que el de pensar de forma libre. La libertad del pensamiento es sustituida por una pseudo-objetividad donde el no compromiso, la neutralidad y el distanciamiento revisten un aura de cientificidad y de aparente rigor. Necesitamos pensar con libertad; tal parece que el pensamiento crítico se ha ido de vacaciones por un plazo indefinido. La estupidez y el conformismo no se oponen a la lógica de la nueva producción científica en la sociedad contemporánea, algo similar habría que señalar de la producción y consumo del arte y de la cultura en el seno de dicha sociedad. Y hoy, preci- samente cuando más urge pensar y pensarnos como sujetos y como sociedad libres, es cuando el pensamiento y la libertad están más ausentes que nunca. Ahora que el capitalismo está mutando de forma radical.

El capitalismo actual se vuelve más flexible, creativo, rizomático, autofagocitador y autocanibal; la flexibilidad y la creatividad se traducen en riesgo, precariedad, inestabilidad e indigencia. Las estructuras e instituciones de control y dominación no desaparecen, pero se evaporan, hacen trizas sus referentes fijos. Un Estado consorte de grandes trasnacionales está expulsando, cotidiana, sistemática y metódicamente, más de la tercera parte de la población mundial. Devorarse a sí mismo, maximizar la ganancia hasta los límites más demenciales y suicidas es una apuesta ciega en la que todos, de una forma o de otra, somos cómplices, la mayoría de forma pasiva, del actual casino capitalista de la globalización. El nuevo orden no abole las reglas del pasado, si no es desde la implementación de mecanismos de opresión más econó- 


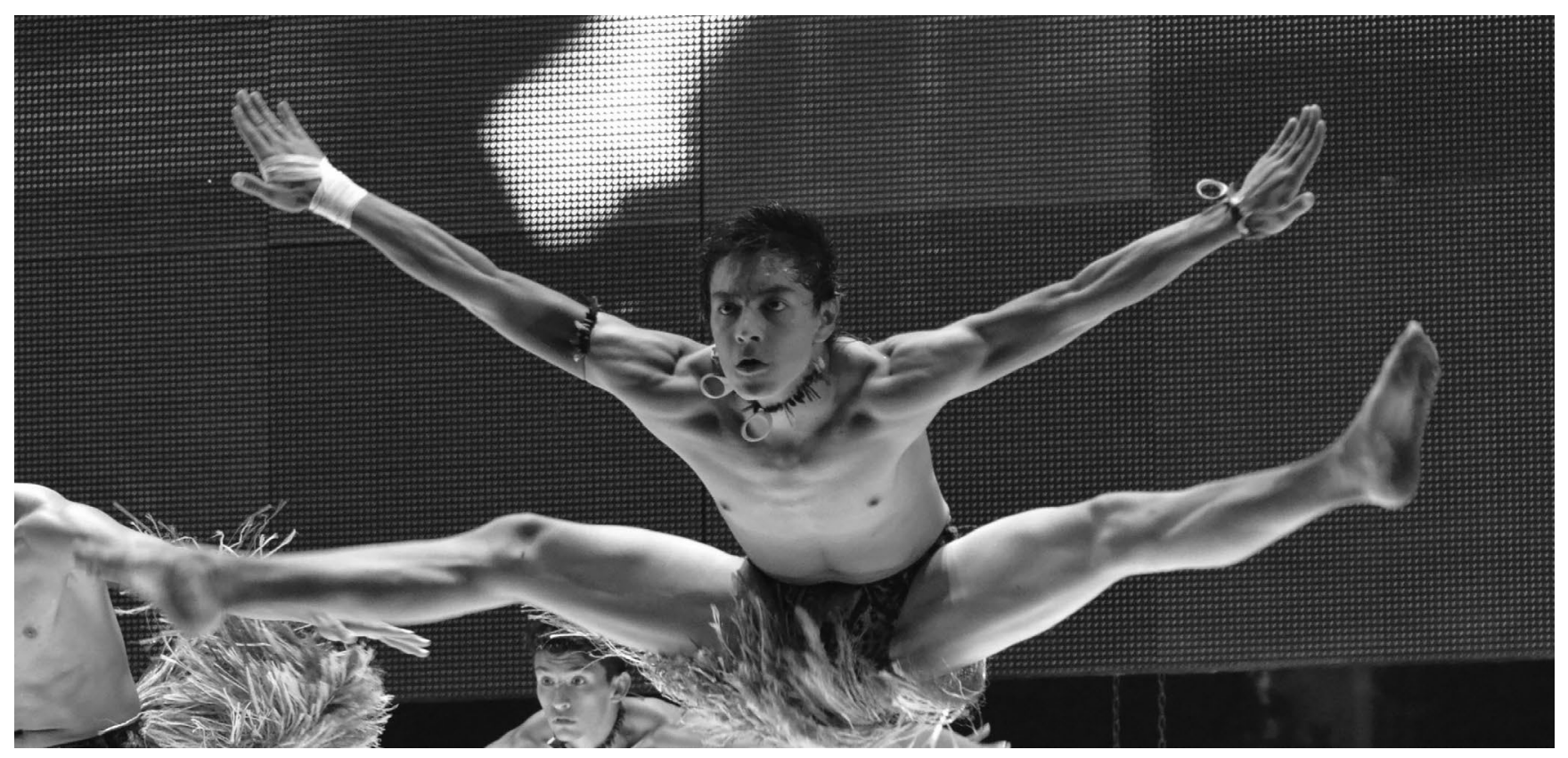

Los usuarios de museos, teatros y salas de concierto conforman una “élite cultural”. El gran público se congrega en espectáculos al aire libre. Aunque la mayoría de los pobladores de colonias periféricas y localidades rurales no acude a las representaciones.

micos, flexibles y autointeligentes. En todo caso, como ha sugerido Richard Sennett,, "el nuevo capitalismo es, con frecuencia, un régimen de poder ilegible”. El carácter ilegible del capitalismo, la sociedad y la cultura actuales se suelen despachar de manera apresurada con las palabras crisis o debacle, pero las ganancias billonarias de las grandes trasnacionales nos muestran que el capitalismo está más vivo que nunca, y que la desregulación, desempleo y ajustes financieros no ponen en crisis una ingente maquinaria global.

Se requiere una redefinición de conceptos básicos como cultura, producción de subjetividad, ciudadanía crítica, consumo cultural, pensamiento crítico, cultura massmediática a partir de nuevas dinámicas sociales, políticas, éticas y estéticas. Mientras que la radicalización de la modernidad tecno-científica revoluciona muchos de los ámbitos de las autodenominadas sociedades avanzadas o postindustriales, sus teóricos se están quedado rezagados; algunos de ellos lo manifiestan. Los profesores Ulrich Beck y Richard Sennett coinciden en el diagnóstico sobre la teoría social: cierre categorial frente a una realidad que resiste la teorización. En Estados Unidos y Europa - según estos científicos sociales -, los investigadores reaccionan ofendidos e irritados y desean seguir investigando como hasta aho- ra, sólo que con métodos perfeccionados. La agenda de la sociedad actual como globalización y nuevas formas de exclusión y colonialismo o son evadidos o son subvalorados desde una perspectiva crítica; lo mismo se aplica, salvo casos excepcionales, a América Latina. Opera una banalización de la crítica seria y fundamentada.

Padecemos en la orfandad teórica una inopia generalizada. Las discusiones guardan una extraña censura respecto a los debates fundamentales:

\footnotetext{
Vivimos en instituciones-zombi e investigamos mediante categorías-zombi; con categorías vivas-muertas que nos hacen ciegos frente a los cambios vertiginosos de la realidad. También en Occidente se sufre el efecto de la Alemania Democrática. Las columnas que soportan el Estado se erosionan: partidos políticos, sindicatos, Iglesia... La fuerza de unión respecto a sus miembros desaparece de la misma manera que su poder de definición de la agenda política. ${ }^{3}$
}

Sennett observa que este no es sólo un problema de los teóricos, sino que también "la gente" tiene problemas para adaptarse a estas nuevas modalidades laborales y de convivencia. La gente insiste en que el trabajo debe fundar su identidad y que la familia debe ser un factor decisivo en tal proceso. 
En el intento de regresar a viejos valores y patrones de conducta se bloquea, al mismo tiempo, de manera autodestructiva y un tanto esquizofrénica, cualquier esfuerzo por crear nuevas orientaciones y significados. Mientras que la cultura de la libertad en las sociedades avanzadas está en peligro de ser aplastada por la lógica del capitalismo tardío, los científicos sociales y los intelectuales, en su mayoría, sólo observan y callan. Al desplazar el objeto de análisis hacia un problema secundario se contribuye a trivializar la teoría. Los problemas más fundamentales y acuciantes de la sociedad son evitados y se diseñan y promueven agendas de investigación ligadas a la ingeniería social del pensamiento hegemónico.

Nuevas formas de violencia ilegales coexisten con la ilegalidad y la delincuencia organizada; terrorismo y narcotráfico no escapan a la lógica del mercado. La idea de comunidad se erosiona desde ficciones virtuales. Asistimos al naufragio de la realidad social, donde la teoría también encalla y se precipita en la insignificancia o se encripta en la academia y la especialización. La parálisis intelectual nos amenaza de continuo. Y esa paralización intelectual "es peligrosa porque no proporciona ninguna herramienta a las personas para que puedan transformar su realidad. En contraposición emerge una avidez de búsquedas, fórmulas y estrategias de orientación" . ${ }^{4}$ Ésta parece ser la gran dificultad en la que hoy nos movemos, sin asideros ni referentes, pero con la exigencia de tener un nuevo norte que oriente nuestras brújulas mentales y sociales.

En tal contexto, las fronteras de la individualización se volatilizan, en un mundo más complejo y cambiante (complejidad y cambios que no sólo están en el entorno sino que también están en los sujetos), y, precisamente, todo esto se efectúa desde la ausencia de criterios y referentes definitivos, los criterios axiológicos de antaño ya no operan. Sin embargo, la narrativa de la quiebra de la modernidad encubre una tesis conservadora y retrógrada que recubre las vicisitudes reales de los procesos de convivencia premodernos. No es que haya menos familias estables, es que ahora están desapareciendo muchos tabúes respecto al divorcio, la familia, el estatus, el rol y la aceptación social. Según Sennett: "la lealtad y la confianza no han desaparecido, solamente han cambiado. Y el problema es: sus formas son tan individuales que ya no conducen a una forma conjunta de negociación política.
Debemos inventar nuevas instituciones que proporcionen durabilidad a la vida de las personas". ${ }^{5}$ La reinvención de lo social se impone como una tarea urgente y apremiante.

Estas exigencias de replanteamiento y renovación de las teorías sociales en América Latina no nos deben ser ajenas, tenemos que ser más sensibles respecto a los intentos de reorientar el saber. Sin embargo, jamás debemos perder de vista la necesidad de interlocución con y desde los contextos, regiones, dinámicas, procesos y campos de análisis propios. Pensar y repensar desde la cartografía de un pensamiento situado y sitiado es clave para potenciar una crítica radical y efectiva del orden realmente existente. No confundir ello con el folclorismo localista de muchos investigadores que simulan originalidad cuando lo único que hacen es reinventar el agua tibia de conceptos y métodos de tradiciones heredadas, la mayoría de las veces asumidos de forma inconsciente. Hacer pensar a la teoría implica replantear las miradas y las lecturas a partir del mundo que habitamos y nos habita, a saber, resituar el pensamiento en función de cartografías y entramados de producción de subjetividad que potencien el pluralismo, las prácticas sociales y discursivas de cara a la democratización de una incipiente participación política. Ahora bien, en este punto es preciso acotar que también asistimos a la resignificación del Estado-nación moderno y sus categorías políticas como ciudadanía, participación política e identidad cultural, entre otras.

Guy Debord, en su obra La Societé du Spectacle de 1967 , ya hacía un análisis precoz de lo que hoy le sucede al binomio sociedad-cultura; explicaba cómo la idea de reemplazar el vivir por el representar implica un empobrecimiento de lo humano, "el consumidor real se torna en un consumidor de ilusiones". ${ }^{6}$ En este mundo de representaciones, de hacer como que hacemos, la crítica pierde su fuerza contracultural y se vuelve complaciente. Para Debord la entronización de la imagen modifica por completo la condición humana misma, las relaciones consigo y con los demás. La totalización del espectáculo como forma de vida humana tiende a disolver la noción de ideología frente a una realidad verdadera.

Por su parte, Adorno, filósofo cuya obra se encuentra vinculada con manifestaciones del arte tales como la música y la literatura, sabía que el individuo-hombre-contemporáneo no podía liberarse de las ataduras impuestas por la sociedad capitalis- 


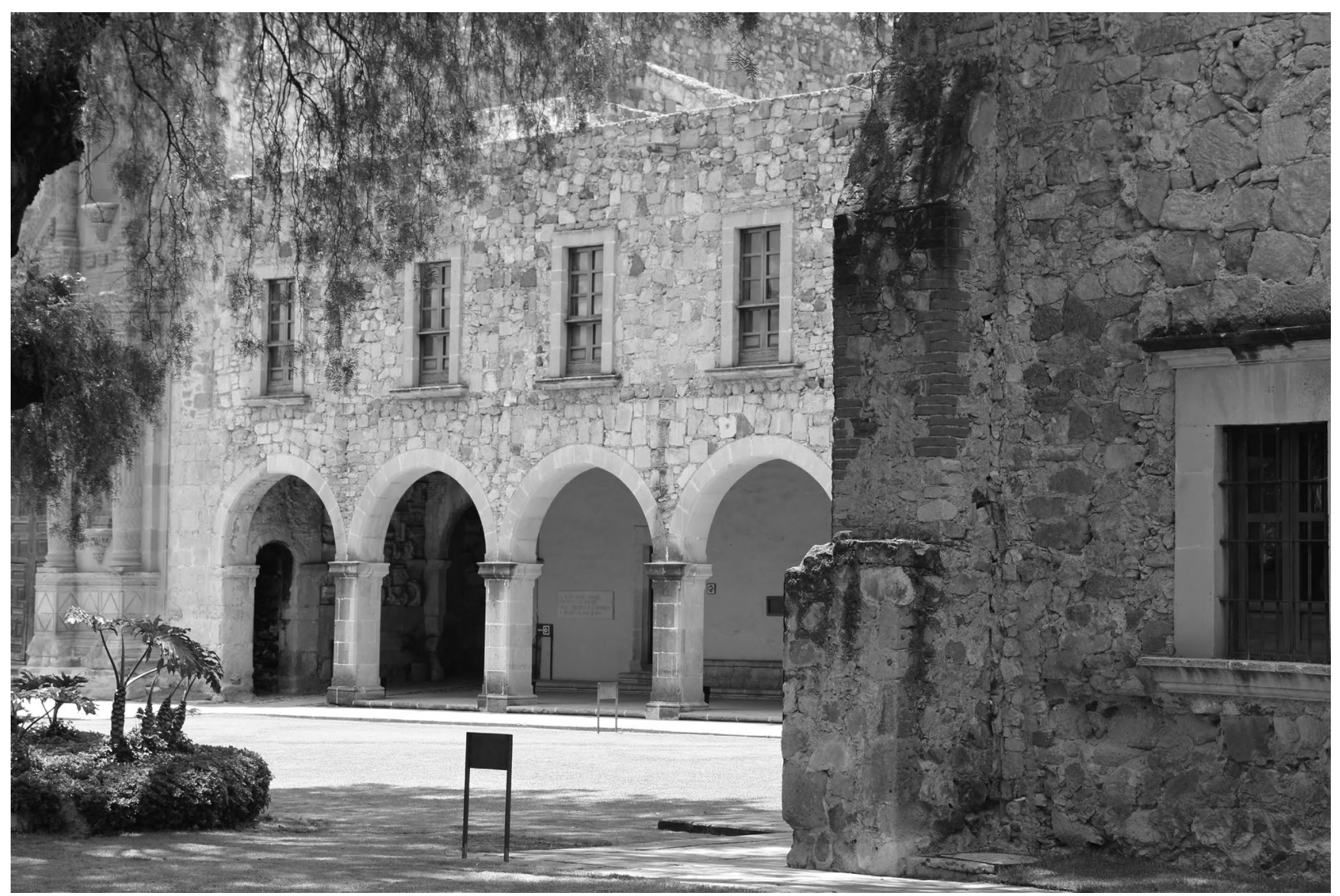

La oferta cultural descansa en la noción de ciudad museo, tanto por el remozamiento del tejido arquitectónico del centro histórico como por la ampliación de la red de museos.

ta si no se apoyaba en las ideas encarnadas del arte. Pero ante la inminente dominación del sistema neoliberal, bajo esta lógica de la ilusión placentera, de pereza y evasión mental, no basta el surgimiento de brotes aislados de buena voluntad. Ni los simples pronunciamientos simbólicos, ni las acciones aisladas de los actores locales son suficientes para encarar las complejas interacciones de las culturas tradicionales con los procesos de industrialización y masificación.?

La cultura de masas quiere ofrecer novedades accesibles al público más amplio posible y que distraigan a la mayor cantidad posible de consumidores. Su intención es divertir y dar placer, posibilitar una evasión fácil y accesible para todos, sin necesidad de formación alguna, sin referentes culturales concretos y eruditos. Este proceso se ha acelerado con la revolución cibernética, la creación de las redes sociales y la universalización del internet. ${ }^{8}$ Internet y el cibermundo que moldea y modela a imagen y semejanza de la cultura de masas tiende hacia la uniformización de la cultura y los sujetos. No es difícil imaginar cómo influyen en el consumo cultural bajos índices de lectura, hábitos masificados en la recepción mediática y poca diversificación intercultural en los gustos, ¿qué puede esperarse de una expansión de tales industrias si éstas no son capaces de apoyarse en un buen nivel educativo?9 Pero esto es sólo una parte del espectro, pues las formas culturales que genera internet son muy complejas y distan mucho de permitir una sola lectura. Aparejada con la domesticación y la dominación, aparecen nuevas estrategias, dispositivos, experiencias y manifestaciones libertarias y de insurrección.

Los estudios sobre consumo cultural muestran que los gastos domésticos suben en la adquisición de "máquinas culturales" - televisión, computadoras, equipos de sonido y video - en detrimento del gasto en libros y espectáculos teatrales. Además, revelan que los públicos masivos mantienen una adhesión preferente a radios y televisoras naciona- 
les, así como la música en la propia lengua. El consumo cultural está en sintonía con la cultura consumista capitalista.

Dado que una práctica cultural no puede ser cuantificada y descrita únicamente por medio de un porcentaje o una cifra, puesto que dicha práctica siempre se realiza dentro de una constelación de otras prácticas y actividades dentro de las cuales tiene sentido, se origina y transforma el tiempo; ${ }^{\circ}$ es necesario trascender los números y hacer un análisis profundo de lo que significan dichas prácticas en la conformación de los sujetos. Por este motivo, las investigaciones cuantitativas sobre las prácticas y consumos culturales no son suficientes para proporcionar nuevos modos de pensamiento y de vida. Si los teóricos e investigadores no comienzan a entrelazar estas cifras con la redefinición de conceptos básicos como cultura, producción de subjetividad, ciudadanía, identidad y consumo cultural, el análisis crítico seguirá siendo un artificio. Habría que analizar e interpretar "el consumo cultural" desde una hermenéutica crítica que conecte subjetividades, sociedad, experiencia, mercado y capitalismo.

La cultura se transmite a través de la familia y cuando esta institución deja de funcionar de manera adecuada el resultado "es el deterioro de la cultura”. La inmensa mayoría del género humano no practica, consume ni produce hoy otra forma de cultura que aquella que, antes, era considerada por los sectores cultos, de manera despectiva, mero pasatiempo popular. Estamos entrando a una nueva fase humana radical donde todo tiende hacia el aplanamiento, la estandarización, la personalización predeterminada, la caducidad y el frenesí consumista. Hoy los productos culturales no pretenden trascender en el tiempo, antes bien, son fabricados para ser consumidos al instante y desaparecer para dar paso así a una serie de nuevos productos igualmente exitosos y efímeros." Incluso la misma industria editorial, otrora un poco más conservadora y apegada a criterios de alta cultura, se dirige a pasos agigantados hacia la venta de novedades sin importar en absoluto su calidad. La cantidad de libros vendidos se traduce en calidad. Del quiebre del canon pasamos, de forma irreflexiva, a la imposición de cánones mercadotécnicos. La misma historia trillada se puede contar a un mismo público pasivo bajo una estrategia distinta de publicidad y mercadeo.

\section{Algunos datos y cifras sobre consumo Cultural en México y Zacatecas}

Los principales espacios en los cuales se realizan estudios de consumo cultural en México son las universidades y otros centros de investigación. Con el desarrollo de una perspectiva antropológica del consumo cultural se ha mostrado que éste constituye una rica veta para explicar transformaciones en el espacio público y el ámbito privado, para entender la importancia de los procesos de consumo en la constitución de identidades. ${ }^{12}$ Aun así, los estudios de consumo cultural están en pañales porque se siguen efectuando, salvo contadas excepciones, desde perspectivas teóricas anquilosadas. Mabel Piccini considera que el mismo espacio público y las identidades de grupos e individuos están amenazados: asistimos a una crisis de lo que tradicionalmente se ha entendido por vida colectiva, sobre todo en las grandes ciudades, crisis de una forma de sociabilidad ligada a las relaciones en el espacio público y a las formas instituidas de la comunicación social, el intercambio político y la acción política en su máxima latitud. El espacio público está siendo secuestrado por la maximización del espacio comercial mediático.

En México, los antecedentes en materia de información sobre temas vinculados con el sector de la cultura están conformados por las diferentes encuestas que de manera regular realiza el Instituto Nacional de Estadística, Geografía e Informática (INEGI), cuyos resultados permiten detallar, al menos parcialmente, algunos elementos como el gasto en productos y servicios culturales; encontramos también la información estadística generada por instituciones como el Consejo Nacional para la Cultura y las Artes (Conaculta), con instrumentos como la Encuesta Nacional de Hábitos, Prácticas y Consumo Culturales. ${ }^{3}$

Por otra parte, el Conaculta ha realizado diversos estudios para captar información sobre el sector cultural, entre los que se encuentran la Encuesta Nacional de Lectura y las encuestas a públicos de museos, teatros, librerías y bibliotecas ubicadas en la Ciudad de México. La publicación más reciente 
corresponde a la Encuesta a públicos de museos en 2009. Su objetivo es conocer el perfil del público que asiste a estos recintos culturales, esto es, elementos como el lugar de residencia, si son visitantes habituales, cómo se enteraron de su existencia, la razón de su visita, la duración de la misma, la opinión sobre las salas, exposiciones y servicios que se ofrecen, entre otros temas.

El interés por las prácticas de consumo cultural es reciente, y tiene aún mucho qué ofrecer. Si estos análisis devienen un área de investigación organizada y continua, es posible pensar en desentrañar algunas de las relaciones que existen entre las cifras de consumo, los grupos y sectores sociales y la nueva dinámica mundial caracterizada por una continua disolución de fronteras y creación de comunidades virtuales. Afirma Jesús Martín Barbero, refiriéndose directamente al público latinoamericano, que los sujetos no son simples consumidores sino interlocutores activos con los productos culturales. ${ }^{14}$ Lo cual tampoco garantiza un consu- mo crítico y reflexivo, pero sí implica ya la búsqueda de una toma de distancia respecto a los objetos e insumos dotados de valor cultural o artístico.

\section{Lectura a nivel nacional y en Zacatecas}

Según la Encuesta Nacional de Lectura (ENL) de 2012 el panorama, en principio, es desalentador, faltaría, además, hacer un análisis a profundidad, pero una conclusión real de este estudio es que en México se lee menos, que la lectura sigue siendo un asunto estrictamente educativo y que el acceso a la cultura escrita está seriamente restringido para la mayoría de la población. El porcentaje de la población que no gusta de leer es de 3 o por ciento de los jóvenes de 12 a I7 años y de 44 por ciento de los adultos mayores de 56 años. Este dato es cruelmente revelador si se piensa que nuestro país ocupa uno de los últimos lugares de lectura en Hispanoamérica.

Si se compara el comportamiento entre 2006 y 2012, se puede observar una disminución significativa en el número de lectores de libros (una caída

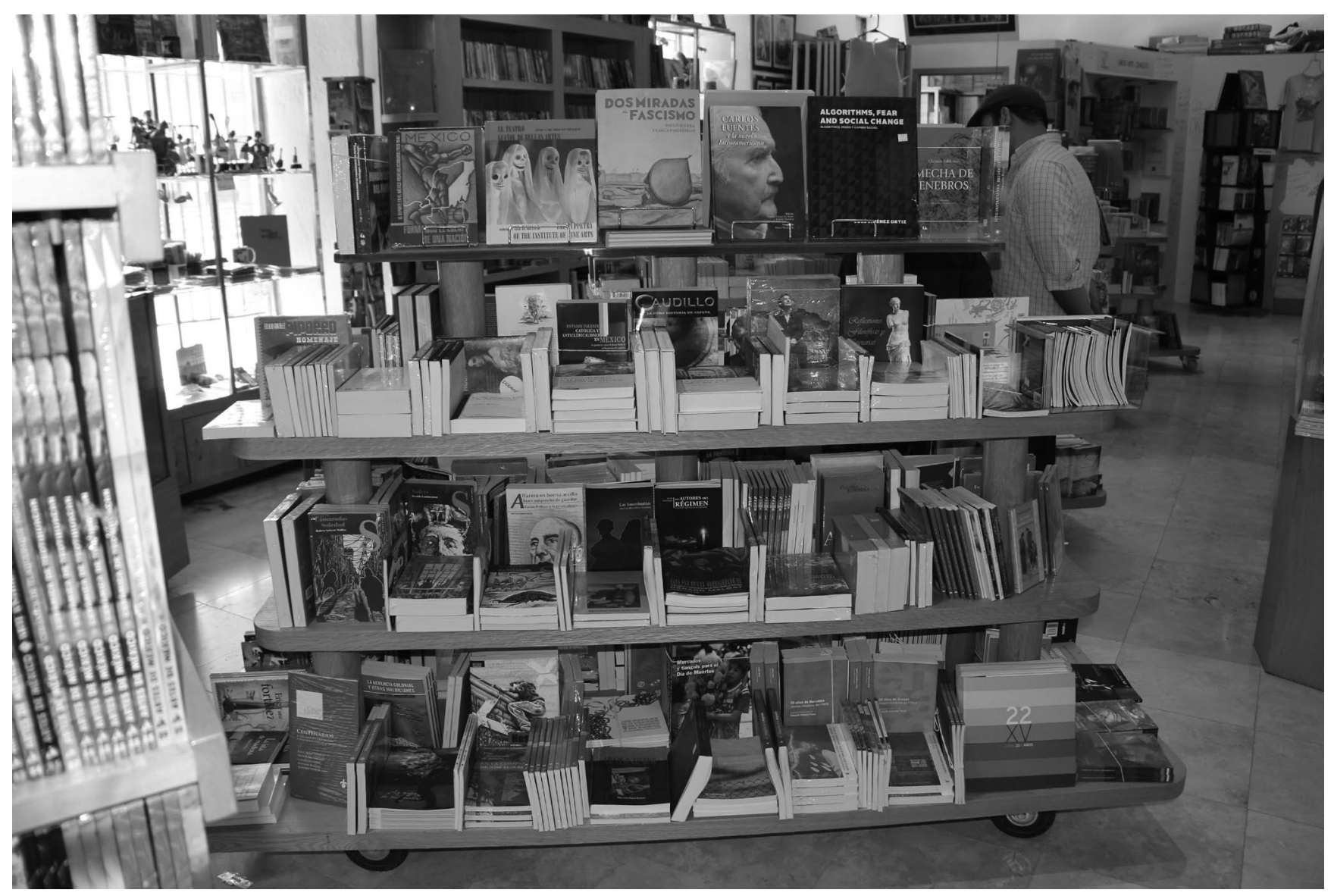

La preeminencia de fuentes informativas audiovisuales y el deterioro del sistema educativo en todos los niveles desalientan la lectura de obras artísticas, científicas y filosóficas. 
de io por ciento). El resultado actual es que más de la mitad de la población ya no lee libros; en México ya es menos de la mitad de la población mayor de I2 años que lee libros, el promedio anual estimado en 2012 es de 2.94 libros por persona. Al respecto resulta significativo que tengamos actualmente como presidente de la República a una persona que no ha leído más de tres libros en toda su vida. El nivel de "analfabetismo funcional" de la clase política podría leerse como síntoma de la descomposición social de la cultura contemporánea.

Dentro de las preferencias por el tipo de material de lectura se encuentran, en primer orden, los medios masivos de información como periódicos y revistas, pero, por lo general, es mayor el grupo de personas que no expresan ninguna preferencia por algún tipo de material de lectura. Así que podemos decir que en términos generales, se lee poco y mal.

Para la formación de un lector adulto, intervienen factores como el capital cultural, es decir, la escolaridad de sus padres y la influencia familiar en la construcción del hábito lector, además de la lectura en solitario, la lectura por la madre o el maestro durante la infancia y la cantidad de libros en los hogares. En nuestro país, la mayoría de la población tiene menos de io ejemplares en casa; en general, 87 por ciento de los hogares mexicanos tienen entre i y 3 o libros (que no sean libros de texto).

Aunque solamente en el grupo de edad que va de I2 a I7 años, las personas siguen leyendo igual o leen más en comparación con el resto de los grupos de edad; esto se debe a la importancia instrumental de la lectura como actividad de estudio y con propósitos escolares bien definidos. Es por ello que se observa una caída en la intensidad de lectura a partir de los i8 años, edad a la que la mayoría de los jóvenes terminan sus estudios (solamente 24 por ciento de los jóvenes de i 8 a 23 estudian) y es cuando leen menos, agudizándose la disminución en la lectura notablemente con el aumento de la edad. Lo anterior significa que los planes y programas de estudio en la formación de lectores están fracasando estrepitosamente en nuestro país.

Curiosamente, en respuesta al cuestionamiento "ile gusta leer?", hay una constante mayor de 5o por ciento en todos los rangos de edad a decir que sí. Dentro del grupo lector, resalta la lectura de libros como el material más importante para la lectura por placer. Dos terceras partes de la población leen por placer menos de treinta minutos diarios o su equivalente; si leen un día a la semana, una o dos horas. En realidad, el dato se acerca más a 20 minutos diarios. En síntesis, las principales razones expresadas por los mexicanos para no leer ahora o por las cuales no leerían son, fundamentalmente, la falta de tiempo, dedicarse a otras actividades recreativas o no les gusta leer.

Al igual que el dato de disminución de la lectura de libros en los últimos años, también ha disminuido significativamente la asistencia a bibliotecas públicas. Las principales razones generales por las que los mexicanos no van a una biblioteca pública es porque no tienen tiempo ( 58 por ciento), porque está muy lejos (29 por ciento) y porque no les gusta leer (29 por ciento); mientras que 22 por ciento van para leer por placer..$^{5 \check{L}}$

Sobre los hábitos de lectura en Zacatecas, las cifras se mantienen en rangos bajos; por ejemplo, hay 72.24 por ciento de personas que no han leído un libro completo (que no se relacione con la escuela o profesión) en un año. Respecto a los medios de información, 54.I5 por ciento no lee nunca el periódico; dentro del grupo que sí lo hace, la secciones más leídas son las noticias nacionales y la policiaca; 56.85 por ciento de personas en Zacatecas no ha leído una revista, quienes lo hacen tienen como su preferido el tema de espectáculos con 5 г.85 por ciento y en segundo orden los deportes con 20.36 por ciento. Si hablamos de cuántos libros tiene un hogar zacatecano en promedio, los datos son: 33.86 por ciento de i a ro libros que no sean de texto contra 28.85 por ciento que no tiene ninguno. ${ }^{16}$ Por tanto, los resultados no pueden ser más desalentadores, vivimos en un mundo donde se leen cada vez menos obras valiosas, vivimos en un país de no lectores, y para colmo de males, vivimos en un estado donde la lectura es un lujo para una élite privilegiada, donde aun dentro de esa clase hay una gran población que no lee ni en defensa propia, como diría un maestro lector.

\section{Los museos}

En Latinoamérica, México es uno de los países que posee una notable infraestructura en museos de antropología, historia y arte, con un total de ı,o58, hoy $\mathrm{I}, 229^{17}$ entre los administrados por instituciones públicas, privadas y comunitarias; pero éstos casi no han crecido en las últimas décadas, ni tampoco ha habido una política de adquisición de 
obras para expandirlos y renovarlos. Esta infraestructura repartida entre la población total del país representa 9 I, 405 habitantes por museo $;^{18}$ en cuanto a la asistencia, a nivel nacional se reporta para 2009-20io un 22.2 por ciento de la población, mientras que para el estado de Zacatecas, sólo 42.8 por ciento ha visitado alguna vez en su vida un museo y 53.8 por ciento nunca lo ha hecho. Entre quienes asisten, 83.3 por ciento de la población asiste una vez al año; el porcentaje podría ser todavía más preocupante si se menciona que en su mayoría se trata de visitas escolares guiadas donde la asistencia tiene un carácter casi obligatorio.

Dentro de los móviles para asistir a un museo, el primero es el entretenimiento o la diversión, y el segundo el aprendizaje. Tanto para Zacatecas como para el país existe una constante de inasistencia e indiferencia hacia espacios culturales, actividades y museos; entre las razones más mencionadas por los mexicanos están la falta de dinero o tiempo, la lejanía, desinterés, aburrimiento o desconocimien- to. En Zacatecas, por ejemplo, las cifras de visitantes a museos entre los años 2007-20II son constantes $^{19}$ con un promedio de 38.25 personas repartidas entre los ocho museos principales de la capital, aunque por las características de la ciudad, la mayoría de estos visitantes son turistas y los periodos de mayor afluencia se identifican en vacaciones, cuando se lleva a cabo el Festival Cultural de Zacatecas, por ejemplo. El museo sigue siendo un espacio para las élites culturales y no logra todavía ser un espacio accesible a las clases sociales desfavorecidas; sigue en lo concerniente al museo una lógica de inclusión minoritaria y exclusión masiva. Habría que democratizar la cultura y su acceso real.

\section{Uso del tiempo libre y el ocio}

Según la Encuesta Nacional de Uso del Tiempo que recaba información de la población de 12 y más años sobre el tiempo dedicado a actividades diversas, entre las que se encuentran las relacionadas con la cul-

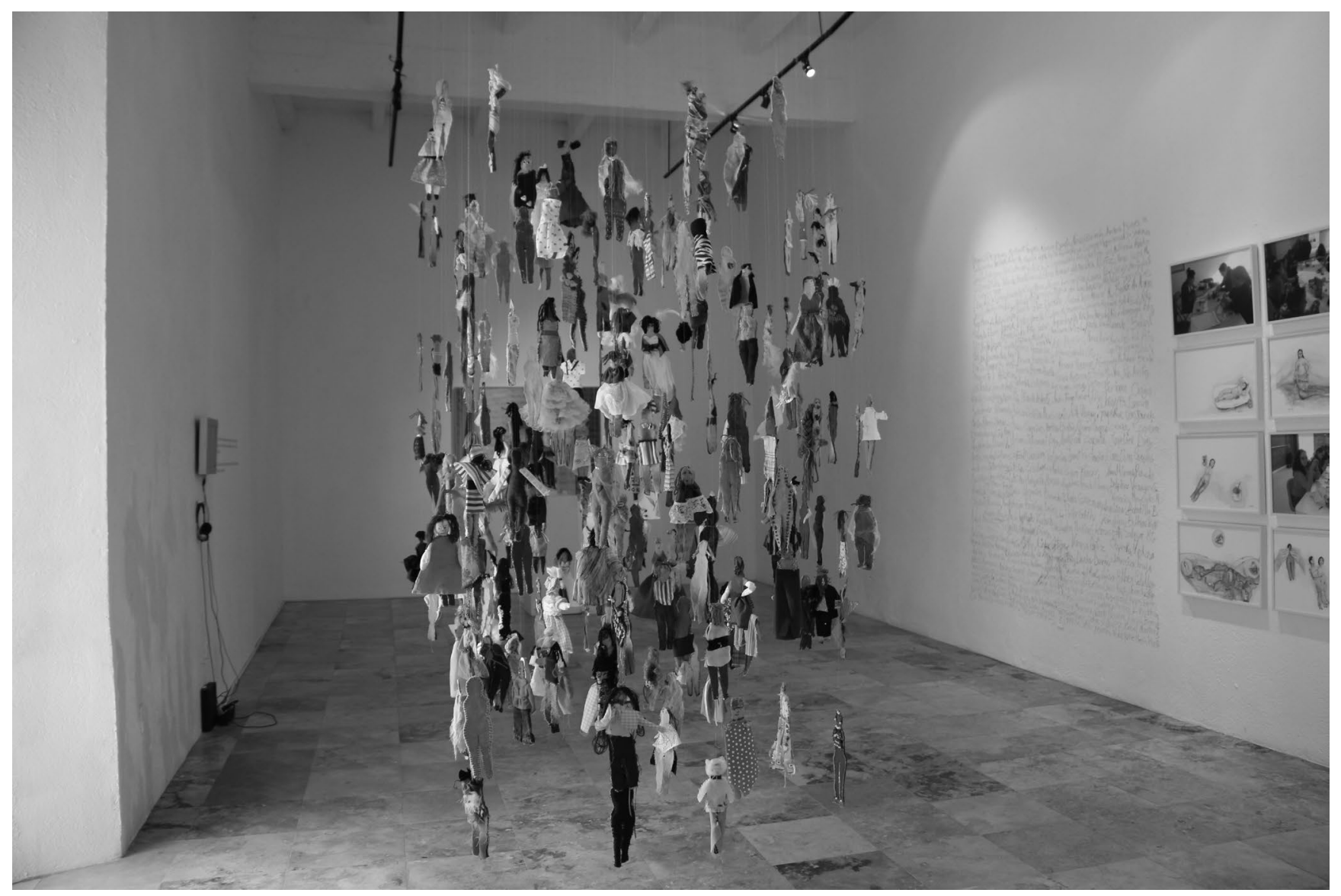

Los artistas críticos no disponen de muchos espacios para exponer la producción y manifestar las ideas. Ocasionalmente encuentran acomodo en los recintos oficiales. 


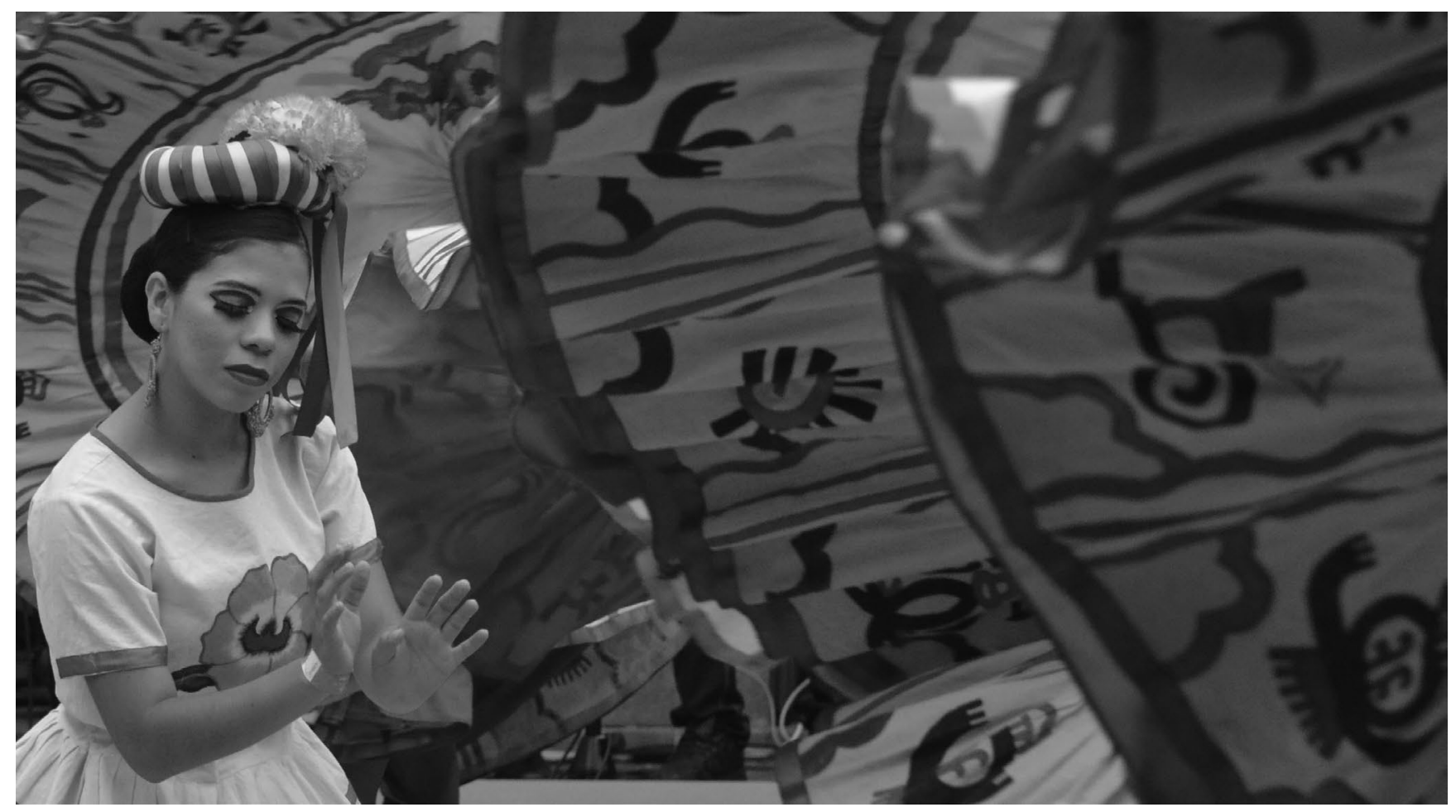

La programación de festivales artísticos, como el dedicado al folclor, pretende atraer turismo en diversas épocas del año.

Foto: Jorge VAzQUEZ.

tura y recreación (como la asistencia a eventos culturales, deportivos y de entretenimiento; participación en juegos y aficiones; deportes y ejercicio físico; así como utilización de medios masivos de comunicación), en 2012, 62 por ciento de la población considerada asistió en el último año al menos en una ocasión a algún sitio o evento cultural.

Dentro de las actividades que conforman parte del quehacer del sector de la cultura, ya sea cine, música, danza, literatura, entre otras, están las ferias y festivales artísticos y culturales que son organizados con el objetivo de presentar y difundir contenidos simbólicos a través de actividades, además de impulsar transacciones económicas entre productores y consumidores, lo que se vuelve de interés para ser captadas por la Encuesta Nacional de Consumo Cultural de México (Enccum). En cuanto a la asistencia de la población a este tipo de eventos en 2012, se observa que casi cuatro de cada Io personas participaron en al menos una ocasión en actividades culturales. Atendiendo a la clasificación por grupos de edad, se observa que del total de personas que asistieron a este tipo de eventos, quienes más lo hicieron fueron aquellas cuya edad oscila entre 3 o y 49 años sumadas en 40 por ciento de la población. Otro tipo de actividades culturales de interés que contempla la Enccum son aquellas efectuadas en la vía pública, entre las que se incluyen presentaciones de música, teatro, danza, pintura, escultura y fotografía. A partir de los resultados obtenidos, se observa que 29 por ciento de la población se detuvo a presenciar de forma voluntaria, al menos en una ocasión, este tipo de espectáculos en 2012, lo que equivale a 12,292 veces el cupo del teatro del Palacio de Bellas Artes. Este dato, que podría ser alentador, dista mucho de serlo si se compara con la capacidad del Estadio Azteca, del Grupo Televisa, con capacidad para ıo5,o64 espectadores, siendo el tercer estadio de futbol más grande del mundo.

En cuanto a la información sobre el interés de la población en adquirir habilidades en áreas afines a la cultura a través de cursos y talleres sobre cine, video, radio, televisión, música, teatro, danza, pintura, escultura, fotografía, canto, dibujo, manualidades, artesanías, actuación, diseño o literatura, se observa que i2 por ciento de la población (objeto de la encuesta) participó de ellas al menos en una ocasión en 2012. 
Con el desarrollo de las nuevas tecnologías y el acceso a éstas, es necesario considerar que cada vez hay más población que utiliza internet, y aumentan entonces las ocasiones y la proporción del consumo de este servicio asociado con actividades susceptibles de ser consideradas parte del sector cultural. El uso de internet por motivos culturales incluye las actividades de comprar libros y revistas; comprar CDs, música, DVDs y software; ver videos, películas o programas de TV; oír música grabada, radio o audiolibros; leer periódicos, revistas o libros; descargar libros, revistas o artículos académicos; descargar música o video; y descargar softsware. En este sentido, se encontró que 46 por ciento de la población del país con seis o más años navegó en internet por motivos culturales al menos en una ocasión durante 2012..$^{20}$ Sin embargo, el uso o abuso de internet generalmente está ligado a redes sociales con contenido trivial, pornografía, violencia y chismes de actualidad.

En síntesis, las actividades culturales que captan un mayor público son las que se refieren a los sitios y eventos culturales seleccionados, es decir, a espacios como teatros, cine, sitios históricos, religiosos, arqueológicos, museos, bibliotecas, entre otros; por lo que resulta importante no perder de vista la heterogeneidad en la composición de las actividades que integran este conjunto.

En segundo lugar le siguen las fiestas tradicionales, ya sean religiosas, cívicas, patrias o carnavales, como fenómeno cultural ligado a las características particulares de la sociedad mexicana, y a las cuales asistió más de la mitad de la población al menos en una ocasión. ${ }^{21}$

No es de extrañarse que en Zacatecas la información sobre las prácticas culturales de la población sea de características particulares, al ser un estado con pocas posibilidades de desarrollo en comparación con el resto del país, con un creciente flujo de actos de violencia, alta tasa de desempleo y deserción escolar. La ciudad capital, en contraste, se conoce como un centro cultural a nivel internacional, denominado Patrimonio Cultural de la Humanidad desde $199^{3}$, con una vasta diversidad museística, y sede de varios eventos internacionales de carácter cultural y artístico al año, dentro de los que se cuentan el Festival Cultural 20í, el Festival Internacional de Teatro de Calle o el Festival Internacional del Folclor. Las últimas emisiones de los festivales culturales han disminuido mucho en calidad y propuestas artísticas, buscándose sobre todo captar, sin mucho éxito, turismo nacional y extranjero. El reciente Festival Cultural recicla - literalmente reutiliza - figuras artísticas decadentes de la cultura massmediática como Vikki Carr y Emmanuel.

En este contexto, las cifras sobre uso del tiempo libre para los zacatecanos arrojan datos como los que siguen: 88.o5 por ciento de la población nunca ha asistido a un centro cultural, $9^{\circ}$ por ciento ve la televisión en su tiempo libre y 36.69 por ciento lo hace más de dos horas al día; dentro de las preferencias de programación televisiva, en primer lugar están las telenovelas y en segundo los noticiarios, las películas mexicanas y los programas de información deportiva. Las actividades de ocio más recurridas que mencionan los zacatecanos son ver la televisión, salir con los amigos, escuchar música (en las preferencias musicales, el primer lugar lo tiene, por mucho, la música popular de banda o regional) e ir de paseo al campo. Cabe mencionar que de la población muestra, la mayoría alcanza apenas el nivel de educación primaria y su sueldo es el mínimo para la zona económica. El dato anterior resulta altamente significativo, pues nos muestra que la sociedad zacatecana tiende hacia la fragmentación, polarización y exclusión sociales más radicales.

Consumo promedio de la sociedad mexicana y zacatecana

Un ejemplo en el cambio de los hábitos de consumo cultural es lo que sucedió con la industria cinematográfica en México, que en i984 registraba 41o millones de personas en las taquillas, mientras que para ı99і recibía apenas ı7o millones. Para 2006, 53.5 por ciento de las películas proyectadas en el país eran de origen estadounidense contra un io.5 por ciento de origen nacional, y el total de espectadores asistentes a una sala de cine se mantenía en I62.5 millones. Los espectadores declaraban que seguían viendo películas, incluso más que antes, pero preferían la comodidad del video y los filmes programados en televisión; estos cambios de hábitos en las prácticas culturales han sido interpretados como un proceso que forma parte de la retracción en los usos públicos del espacio urbano y el repliegue a la vida doméstica, los avances tecnológicos de la cultura a domicilio ha modificado, entre otras cosas, el acceso al cine. Tanto así, que el aumento de suscriptores a televisión restringida aumentó de 1994 a 2006 en i6.3 por ciento y los hogares 
con acceso a tecnologías de la información entre 2004 y 2006 aumentaron de 35.3 a 47 por ciento. Para 2012 es notable el incremento en uso de internet por la población, así como el aumento en su frecuencia de uso. Internet está desplazando a la televisión de manera apabullante.

Las cifras de 2012 en comparación a las recabadas en el 2006 varían considerablemente; las personas que afirman utilizar internet equivalen a 43 por ciento de la población que era antes de 24 por ciento; 44 por ciento dice usar internet diario mientras que hace seis años este porcentaje era apenas de 5.3 por ciento.

El 37 por ciento usa internet varias veces a la semana en comparación con 9.5 por ciento que lo hacía en 2006. En los lectores, las principales razones para usar internet están relacionadas con la comunicación; en los estudiantes, con la búsqueda de información para trabajos escolares, entretenimiento y relaciones sociales. ${ }^{22}$

Otro ejemplo es la lectura y el consumo de libros. La población total de México es de II2'336,538 habitantes y existen i,533 librerías en todo el país, lo cual da un promedio de 73,278 individuos por librería, de los cuales, a nivel nacional 86.7 por ciento no va a una librería una sola vez al año. En Zacatecas el total de librerías es de I/ y sólo 8.3 por ciento de la población en el estado asiste a una al menos una vez al año, entre esta población se encuentran los universitarios, profesores y estudiantes. Ahora bien, faltaría otro estudio a profundidad que nos muestre qué es lo que se lee y cómo se lee, para seguir documentando el pesimismo y la inquietud.

Asistencialismo, cultura CONFORMISTA Y BROTES INCIPIENTES DE PARTICIPACIÓN AUTO-GESTIVA

En México se ven favorecidos los proyectos a gran escala, en contraste con la escasez de equipamientos proporcionales a la expansión urbana, esto reitera la tendencia a enfrentar necesidades estructurales con obras-espectáculo y golpes efectistas. En vez de políticas socioculturales que atiendan necesidades y desigualdades locales en la oferta y el acceso a los bienes, se busca una marca o un estatus que venda. ${ }^{23}$ No hay políticas culturales de mediano o largo plazo en nuestro país que consoliden un consumo cultural crítico, reflexivo y que tiendan a la formación de públicos inteligentes.

En el fondo, falta aún la presión organizada de la sociedad civil, ya que la democratización es aún incipiente: faltan movimientos de consumidores, de televidentes y formas de representación ciudadana de los derechos comunicacionales y culturales. ${ }^{24}$ No hay una participación activa de la población, sino pequeños brotes esporádicos, marginales, aleatorios. El panorama es muy complejo, porque se cuenta con gran potencial en todos los ámbitos culturales y artísticos, pero sin una participación organizada, sistemática, planeada.

Aún y cuando las cifras dicen lo contrario, México cuenta con una gran infraestructura en cuanto al ámbito cultural se refiere. Tal vez sea ésta una de las razones para la complicación y poca efectividad, hablando a nivel de impacto social y desarrollo. Esto nos permite asumir que el problema no es sólo el dinero y los recursos, sino la generación de políticas culturales horizontales, transversales y comunitarias. Aquí sería preciso señalar que no todo depende de las instituciones culturales, sino que exige públicos más críticos, sujetos empoderados y autogestivos capaces de sortear de forma creativa los diversos impedimentos materiales, sociales, técnicos y estéticos. La creatividad social siempre será trabajar en contra de los límites impuestos.

\section{Hacia la democratización de la cultura, UNA NUEVA CIUDADANÍA CRÍTICA}

Una política cultural democrática requiere superar las formulaciones dirigistas y vincular orientaciones globales con demandas reales de la población. ${ }^{25}$ Las concepciones democráticas de la cultura - entre ellas las teorías liberales de la educación - suponen que las diversas acciones pedagógicas que se ejercen en una formación social colaboran armoniosamente para reproducir un capital cultural que se imagina como propiedad común.

La política cultural abarca una amplia gama de aspectos como la música, los monumentos, la investigación cultural, el cine, la ciencia, el teatro, la arquitectura, los libros, los medios, el juego, las artes plásticas, las artesanías, las danzas, por dar sólo unos ejemplos, y es por esta razón que resulta 
tan complicado elaborar una política única de desarrollo que abarque de manera puntual cada una de las áreas, porque estos diferentes objetos no siempre dependen de una sola y misma administración. Las políticas públicas pocas veces dimensionan objetivos coherentes a la realidad social. Con el neoliberalismo las políticas y las instituciones son cuestionadas y reabsorbidas por lo privado. Hay un debilitamiento notorio del Estado de bienestar, mismo que creó estos establecimientos para llevar a cabo sus funciones; la privatización de la cultura va de la mano de la privatización del es- pacio público. Por desgracia, muchas de las políticas todavía se piensan desde la visión moderna del desarrollo. Queda entonces pendiente saber cómo las políticas culturales pueden sacar provecho de estos nuevos cambios, haciendo uso de las facilidades técnicas, del reacomodo de lo social y de los procesos multiculturales que se viven en México y Latinoamérica. La emergencia de nuevas subjetividades subversivas y emancipadas tal vez podría ser una nota discordante en el concierto monocorde de una globalización cultural uniformizante y neutralizadora.

\section{- notas $\cdot-$}

'Adorno (2003), Mínima Moralia. Reflexiones desde la vida dañada, Madrid, Taurus, p. 123.

${ }^{2}$ Richard Sennett (2000), La corrosión del carácter, las consecuencias personales del trabajo en el nuevo capitalismo, Barcelona, Anagrama, p. Io.

${ }^{3}$ Ulrich Beck y Richard Sennett (200o), "En busca de una nueva orientación. Conversación entre Ulrich Beck y Richard Sennett", Archipiélago, núm. 44, p. 126.

4Ulrich Beck y Richard Senett, op. cit., pp. 127-132.

${ }^{5}$ Idem.

${ }^{6}$ M. V. Llosa (2012), La civilización del espectáculo, México, Alfaguara.

'Ernesto Piedras Feria, N. G. (2008), Las industrias culturales y el desarrollo de México, México, Siglo XXI.

${ }^{8}$ M. V. Llosa, op. cit.

${ }_{9}$ Ernesto Piedras Feria, N. G., op. cit.

${ }^{\circ} \mathrm{A}$. R. Mantecón (s.f.), Los estudios sobre consumo cultural en México, México.

"M. V. Llosa, op. cit.

${ }^{12}$ A. R. Mantecón, op. cit.

${ }^{13}$ Instituto Nacional de Estadística, Geografía e Informática (INEGI) (20I4), Encuesta Nacional de Consumo Cultural de México 2012, Aguascalientes, México.

ı́Mónica Szurmuk, R. M. (2009), Diccionario de estudios culturales latinoamericanos, México, Siglo XXI, Instituto Mora.
${ }^{15}$ Fundación Mexicana para el Fomento de la Lectura, A.C. (io de febrero de 2013). miguelcarbonell.com. Recuperado el 8 de mayo de 20I4, de http:/www.miguelcarbonell.com/ artman/uploads/ı/ENL_2or2.pdf

${ }^{16}$ Consejo Nacional para la Cultura y las Artes (Conaculta) (2013), Sistema de Información Cultural. Recuperado en mayo de 20r4, de http://www.conaculta.gob.mx/encuesta_nacional/.

${ }^{7}$ Ibidem. Recuperado en mayo de 20I4, de http://mapa.sic. gob.mx/.

${ }^{8}$ I dem.

${ }^{19}$ Gráfica Visitantes de museos al día en los años 200720Ir. Centro Histórico de Zacatecas, una coyuntura a favor de la sostenibilidad. Junta de protección y conservación de monumentos y Zonas típicas del Estado de Zacatecas.

${ }^{20}$ Instituto Nacional de Estadística, Geografía e Informática (INEGI) (20I4), Encuesta Nacional de Consumo Cultural de México, Aguascalientes, México.

"Ídem.

${ }^{22}$ Consejo Nacional para la Cultura y las Artes (Conaculta) (2006), Sistema de Información Cultural. Recuperado el 20i4, de http://sic.conaculta.gob.mx/publicaciones_sic/ebcmV2.pdf.

${ }^{23}$ Ernesto Piedras Feria, N. G., op. cit.

${ }^{24}$ A. R. Mantecón (s.f.), op. cit.

${ }^{25}$ Mantecón, A. R. (s.f.), op. cit. 
Unidad Académica de Estudios del Desarrollo

Red internacional de Desarrollo, Sustentabilidad y Seguridad Humana

A través del Seminario Permanente del Desarrollo

Presenta la conferencia:

\section{UNA RETROSPECTIVA SOBRE LOS EFECTOS DEL TLCAN EN MÉXICO 1994-2014} de James M. Cypher

Comenta: Roberto Soto Esquivel, UAED-UAZ

\section{Lunes} septiembre 2014 11:00 hrs.

\section{ENTRADA LIBRE}

Salón de Doctorado

Campus Universitario II

Av. Preparatoria $s / n$

Col. Hidráulica

Zacatecas, Zac.

Tel. (492) 8996945

www.estudiosdeldesarrollo.net 